\title{
Insight into pH-Dependent Formation of Mn Oxide Phases in Electrodeposited Catalytic Films Probed by Soft X-Ray Absorption Spectroscopy
}

\author{
Maryam N. Shaker, ${ }^{1,2}$ Shannon A. Bonke, ${ }^{3}$ Jie Xiao, ${ }^{4}$ Munirah A. Khan, ${ }^{4}$ \\ Rosalie K. Hocking, ${ }^{5}$ and Marc F. Tesch ${ }^{\star 4}$ \\ In memory of Leone Spiccia
}

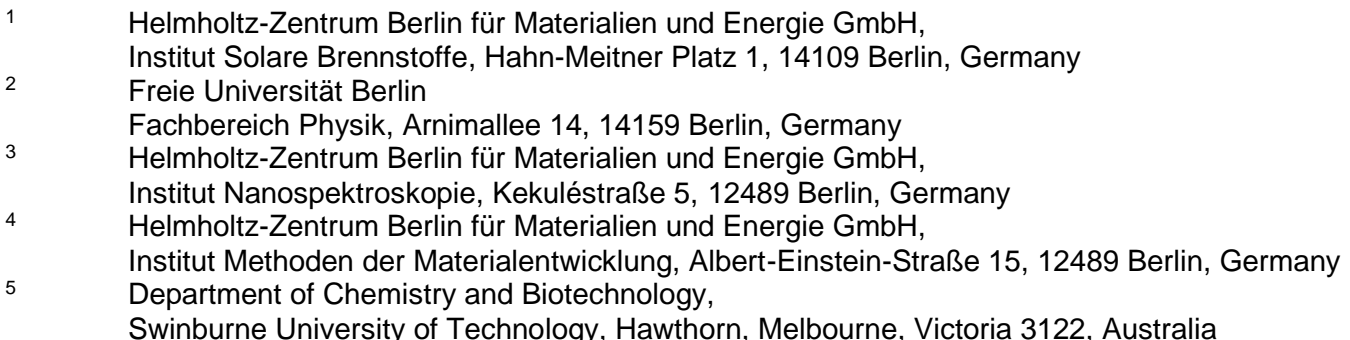

\begin{abstract}
MnO}_{x}$ films electrodeposited at basic, neutral, and acidic conditions from an ionic liquid were investigated by means of $\mathrm{X}$-ray absorption spectroscopy at the manganese $\mathrm{L}_{2,3}$-edges and the oxygen $\mathrm{K}$-edge. Such films can serve as catalysts for the water oxidation reaction. Previous studies showed that the catalytic activity could be controlled by a variation of the deposition parameters, which influence the formation of $\mathrm{MnO}_{\mathrm{x}}$ phases and the film composition. Herein the film compositions are investigated in detail, indicating different ratios of $\mathrm{MnO}_{x}$ structural phases in the films. All films in the series predominately consist of varying proportions of three $\mathrm{MnO}_{x}$ phases $-\mathrm{Mn}_{2} \mathrm{O}_{3}, \mathrm{Mn}_{3} \mathrm{O}_{4}$, and birnessite, while an increase of the average $\mathrm{Mn}$ oxidation state in the film is identified when going from basic to acidic conditions during electrodeposition. The contribution of these three phases shows a systematic dependency on the $\mathrm{pH}$ during electrodeposition. While no specific single $\mathrm{MnO}_{x}$ phase was found to dominate the composition of samples with previously found high catalytic activity, the X-ray spectroscopic results revealed the compositions of those samples close to neutral conditions to be most sensitive when changing the $\mathrm{pH}$.
\end{abstract}

\section{Introduction}

The development and improvement of catalytic materials are a major milestone towards the effective use of sunlight driven water splitting as a renewable energy source..$^{[1-5]}$ Manganese oxides $\left(\mathrm{MnO}_{\mathrm{x}}\right)$ fulfill key criteria for water oxidation catalysts, e.g., they are composed of innocuous and abundant elements, show promising catalytic activity, as well as mimicking the $\mathrm{CaMn}_{4} \mathrm{O}_{5}$ catalyst within Photosystem-II. ${ }^{[6-11]}$ Although there is great interest in $\mathrm{MnO}_{x}$ as a water oxidation catalyst, ${ }^{[12-19]}$ the search for an optimum $\mathrm{MnO}_{\mathrm{x}}$ structure, composition, and morphology is ongoing. ${ }^{[20-22]} \mathrm{MnO}_{x}$ exists in various structural phases, with each exhibiting very different catalytic activities towards water oxidation. The thermodynamically favoured $\mathrm{MnO}_{\mathrm{x}}$ structural phase is highly $\mathrm{pH}$ dependent and typically indicated by the Pourbaix diagram, however, prediction of the formed phases is complicated by kinetic barriers. The wide variety of structures that may be formed, and thus Mn valences, creates a challenge for producing efficient $\mathrm{MnO}_{x}$ catalysts, which is compounded by the effects of extensive structural disorder in many active catalysts. Identifying the dominant structural motifs in largely amorphous films can be very challenging. Soft $X$-ray spectrsocopy is exceptionally sensitive to differences in redox states and electronic structure. For this reason, it is employed herein to determine the structural phases formed by electrodeposition of $\mathrm{MnO}_{x}$ films from water in ionic liquid with systematically varied $\mathrm{pH}$.

Among a variety of other preparation methods, ${ }^{[12,14,23-27]}$ electrodeposition is advantageous as it allows precise control of the formation rate and conditions through control of the applied potential - and consequently the driving force for the film formation. The electrodeposition of catalytically active $\mathrm{MnO}_{\mathrm{x}}$ has been studied in detail, ${ }^{[16,19,28,29]}$ with the deposition and testing 
solution $\mathrm{pH}$ being a variable of importance. ${ }^{[19,28]}$ While an active catalyst must be functional in water, preparing the catalyst in aqueous solution does impose limits on the conditions applied. In this study, a mixture of ionic liquid (90\%) and water (10\%) was used as deposition solution, forming an electrolyte with unusually large cations and anions present, which will in turn affect activity and deposition of materials. Further, it enables to expand the range of temperature beyond that of a typical aqueous solution, while also altering the acidity. ${ }^{[30]}$ An ionic liquid (IL) is a liquid salt at ambient or near ambient conditions, viz. it is a liquid composed of only anions and cations. Using an $\mathrm{IL}$ in combination with varying the $\mathrm{pH}$ during electrodeposition was shown to allow the formation of films that are catalytically active towards water oxidation. The IL allowed depositions at a temperature exceeding the water boiling point, while the acidity variation strongly influenced the morphology and structural phase of the final film. ${ }^{[30]}$

The films were formed by oxidatively electrodepositing $\mathrm{MnO}_{x}$ onto fluorine-doped tin oxide (FTO or $\mathrm{F}: \mathrm{SnO}_{2}$ ) from $\mathrm{Mn}(\mathrm{II})$ acetate in a mixture of the ionic liquid, ethylammonium nitrate $\left(\mathrm{EAN}, \mathrm{EtNH}_{3} \mathrm{NO}_{3}\right.$ ), and water, at $120{ }^{\circ} \mathrm{C}$ varied in $\mathrm{pH}$ by the addition of either nitric acid or ethylamine. This preparative approach was defined in a previously conducted study ${ }^{[30]}$, with the samples examined therein by means of voltammetry, X-ray diffraction, energy dispersive X-ray analysis, and scanning electron microscopy. The dominant structural motif within the films was found by fingerprint comparisons between $\mathrm{Mn} \mathrm{K}$-edge X-ray absorption spectroscopy of samples and reference spectra (X-ray Absorption Near Edge Structure and Extended $X$-ray Absorption Fine Structure). Thereby, it could be identified that variation of the $\mathrm{pH}$ during electrodeposition has a large influence on the structure/composition and morphology, as well as the catalytic activity towards the oxygen evolution reaction (OER). In particular, the previous hard XAS at the Mn K-edge hinted at the contribution of multiple $\mathrm{MnO}_{x}$ phases. ${ }^{[30]}$ However, the observation of subtle changes in the films and mixtures of different structural motifs was limited, as was the surface sensitivity. Thus, the underlying reason for the surface-areanormalised catalytic differences between the samples remained unclear.

In order to identify compositional differences that might be the origin for the previously observed variation in catalytic activity of the samples, the present study examines the films via soft $X$-ray absorption spectroscopy (XAS) in total electron yield (TEY) mode. Due to the short electron escape depth of only a few $\mathrm{nm}$ this method is very surface sensitive. Moreover, it enables the identification of $\mathrm{MnO}_{x}$ phases present in the samples, and due to the detection of dipole allowed $2 p-3 d$ transitions it can reveal even small changes in the $3 d$ valence electronic structure, which plays a key role for the catalytic activity. XAS in the soft X-ray

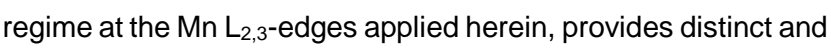
unique spectral features for different oxidation states in addition to changes in the chemical environment. ${ }^{[31]}$ Thus, it allows the $\mathrm{Mn}$ oxidation state to be determined, as well as identification of the structural phases. The additional analysis of the O K-edge gives complementary information about the investigated system.

\section{Results and Discussion}

The samples deposited at different $\mathrm{pH}$ consist predominately of a mixture of three $\mathrm{MnO}_{\mathrm{x}}$ phases. Although the identification of the amount of a particular phase is challenging, it is shown that by comparing each X-ray absorption (XA) spectrum to manganese oxide reference samples with a well-known structure, the contribution of a single phase can be determined. This was achieved using a fitting algorithm handling the XA spectra as a superposition of spectra from specific $\mathrm{MnO}_{x}$ phases.

A soft X-ray analysis was performed on a series of $\mathrm{MnO}_{x}$ samples electrodeposited onto an FTO anode. The samples were prepared from the ionic liquid, ethylammonium nitrate at $120^{\circ} \mathrm{C}$, with a variation of the $\mathrm{pH}$ from acidic to basic during electrodeposition (for details see the experimental section in the supporting information (SI) and Ref. ${ }^{[30]}$ ). The samples are henceforth denoted as $A 3, A 2, A 1, E 0, B 1, B 2$, and $B 3$ in order of increasing $\mathrm{pH}$ with ' $\mathrm{A}$ ' indicating acidic while ' $\mathrm{B}$ ' denotes basic deposition conditions. The sample E0 was prepared under near neutral conditions. Through comparison of the normalized catalytic activity, ${ }^{[30]}$ the previous study showed higher activity for samples E0, A1, and B1. Sample E0 was identified as the most efficient catalyst, followed by those prepared at slightly acidic and basic conditions (A1 and B1, respectively). XAS was applied to identify how the phase composition changes when varying the $\mathrm{pH}$, by studying the samples in an element selective fashion by tuning the energy of the incoming $X$-rays to the $O$ $\mathrm{K}$-edge and $\mathrm{Mn} \mathrm{L}_{2,3}$-edges. All the XAS measurements were conducted in TEY mode.

$\mathrm{Mn} \mathrm{L}_{2,3}$-edges $\mathrm{X}$-ray absorption spectra in an energy range from 635 to $663 \mathrm{eV}$ are shown in Fig. 1, with electronic core-valence transitions induced by the incident soft $\mathrm{X}$-rays leading to two multiplet structures. The first structure from 639 to $648 \mathrm{eV}$ originates from $M n 2 p_{3 / 2} \rightarrow 3 d$ transitions ( $L_{3}$ edge) and the structure between 650 and $658 \mathrm{eV}$ is caused by $\mathrm{Mn} 2 p_{1 / 2} \rightarrow 3 d$ 
transitions ( $\mathrm{L}_{2}$ edge). The spectra in the top panel of Fig. 1 are separated into three groups according to the $\mathrm{pH}$ conditions: basic (group 'B', top), neutral (E0, middle), and acidic (group 'A', bottom). These spectra are also shown overlaid in Figure $S 1$. XAS is sensitive to the local electronic structure with the morphology of the sample having a negligible effect on spectral shape. Thus, although the morphology of the samples within groups 'A' and 'B' was shown to be distinct, ${ }^{[30]}$ the shape of the absorption spectra within the groups is quite similar indicating a similar composition of $\mathrm{MnO}_{\mathrm{x}}$ phases for each group. By comparing the spectra of group 'A' and group 'B', clear differences in the spectral shape can be observed. The spectra of group 'B' exhibit a broad $\mathrm{L}_{3}$ main feature with several high and low energetic shoulders while the $L_{2}$ main peak has a clearly separated shoulder at the low energy side. On the other hand, the spectra of group 'A' show a clear double peak structure at the $L_{3}$ edge while the $L_{2}$ edge exhibits a broad feature without a clearly distinguishable low energy shoulder. According to its deposition conditions, sample E0 exhibits an intermediate spectral shape compared to the ' $A$ ' and ' $B$ ' samples. The spectra of each of the three groups exhibit distinct features (exemplified by dashed lines in Fig. 1), which coincide with spectral features of reference materials (see Fig. 1 bottom panel, Fig S2, as well as spectra from literature ${ }^{[31,32]}$. This indicates a change in the ratio of coexisting phases. Going from group 'B' to group ' $A$ ' a high energy feature appears at the L3 edge, which can also be observed for reference spectra of phases with high average oxidation state. This indicates an increase of the mean $\mathrm{Mn}$ oxidation state of the samples with decreasing $\mathrm{pH}$ during electrodeposition. This is further supported by the change in the shape of the $L_{2}$ edge. For group ' $B$ ' the $L_{2}$ edge exhibits a separated shoulder (blue arrow in Fig. 1 ), which is missing for the samples of group ' $A$ '. A shoulder at this position can be found for reference samples that contain a high amount of $\mathrm{Mn}^{3+}\left(\mathrm{Mn}_{2} \mathrm{O}_{3}\right.$ or $\left.\mathrm{Mn}_{3} \mathrm{O}_{4}\right)$ while no feature at this energetic position can be found for reference samples with a high $\mathrm{Mn}^{4+}$ content $\left(\mathrm{MnO}_{2}\right.$ and birnessite). This indicates that the samples of group ' $A$ ' contain a higher proportion of $\mathrm{Mn}^{4+}$, while sample $\mathrm{EO}$ and the samples of group 'B' contain more $\mathrm{Mn}^{3+}$. Interestingly, the energetically lowest feature - a shoulder at $640 \mathrm{eV}$ - has its lowest intensity for sample E0 (red arrow in Fig. $1 \& \mathrm{~S} 1$ ). The energetic position of this feature is comparable to the position of the lowest feature in the $\mathrm{Mn}^{2+}(\mathrm{MnO})$ and $\mathrm{Mn}_{3} \mathrm{O}_{4}$ reference spectra, and therefore is expected to be caused by $\mathrm{Mn}^{2+}$ (cf. Fig. 1 bottom panel and Fig. S2). This indicates sample EO has the lowest percentage of this $\mathrm{Mn}$ oxidation state. A detailed discussion untangling the contributions of $\mathrm{Mn}$ phases will be given later.

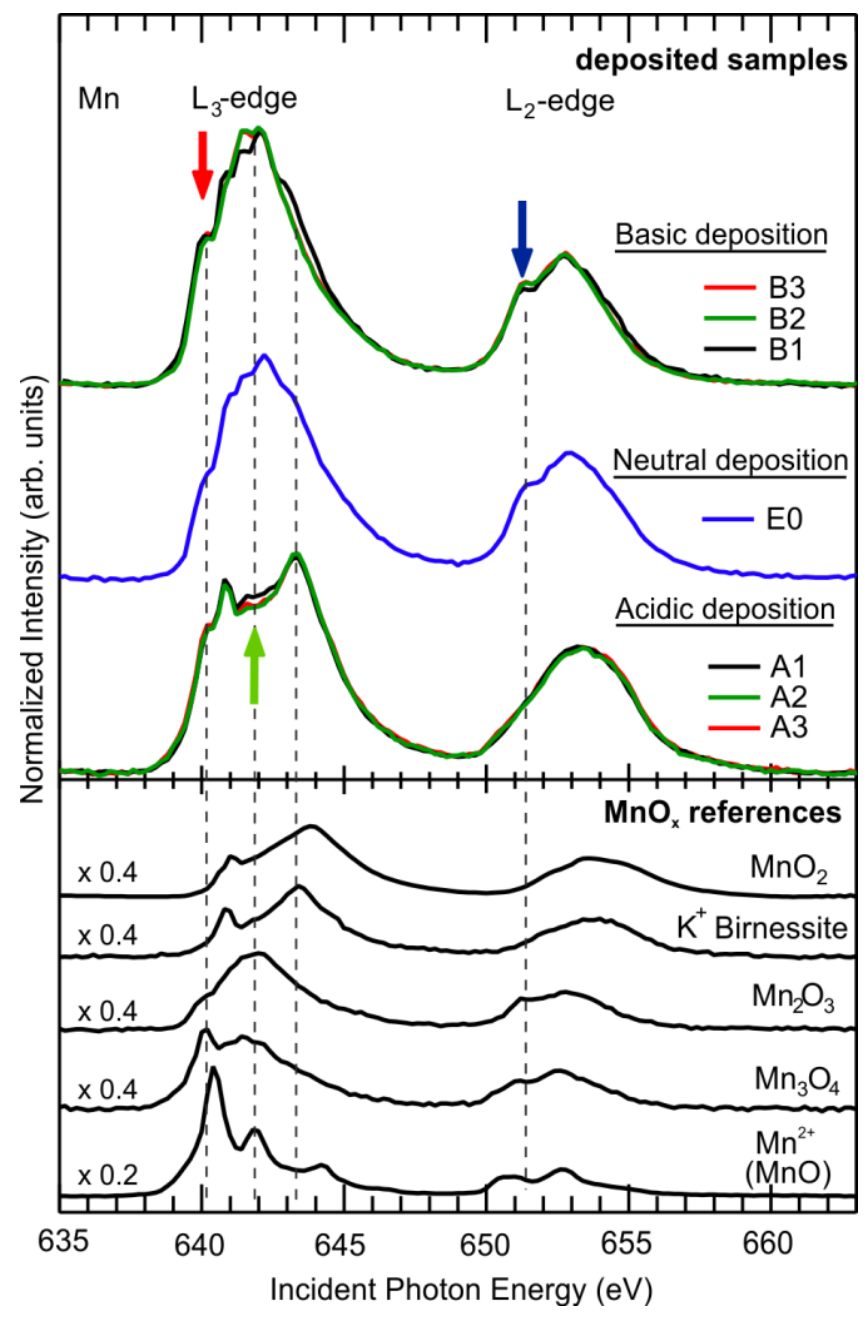

Figure 1. Top panel: Comparison of the $\mathrm{Mn} \mathrm{L}_{2,3}$-edges absorption spectra measured in total electron yield mode for the samples deposited under basic ('B', top), neutral ('E0', middle), and acidic ('A', bottom) conditions. These spectra are plotted on the same axis in Figure $S 1$ to facilitate comparison. Bottom panel: $M n L_{2,3}$-edges absorption spectra measured on reference samples (for details see SI). The arrows and dashed lines indicate features referred to in the main text.

Samples E0, A1, and B1 were indicated by MacFarlane and colleagues as the most active catalysts amongst the investigated sample set. ${ }^{[30]}$. This determination was reached after the catalytic activity was normalised to the electroactive area, minimizing the influences of the sample morphology when comparing the activity for OER catalysis. Interestingly, the XAS spectra for samples $A 1$ and $B 1$ are more in-line with their respective groups rather than being particularly similar to each other. Thus, a closer look has to be taken at the $\mathrm{X}$-ray absorption (XA) spectra to reveal changes in the sample composition. Indeed, the samples $A 1$ and $B 1$ show weak but distinctive spectral differences compared to the spectra for the less efficient catalysts in groups ' $A$ ' and ' $B$ ', respectively. These differences are most pronounced at the $L_{3}$ edge in the energy region ca $641.6 \mathrm{eV}$ (green arrow in Fig.1 \& S1). 


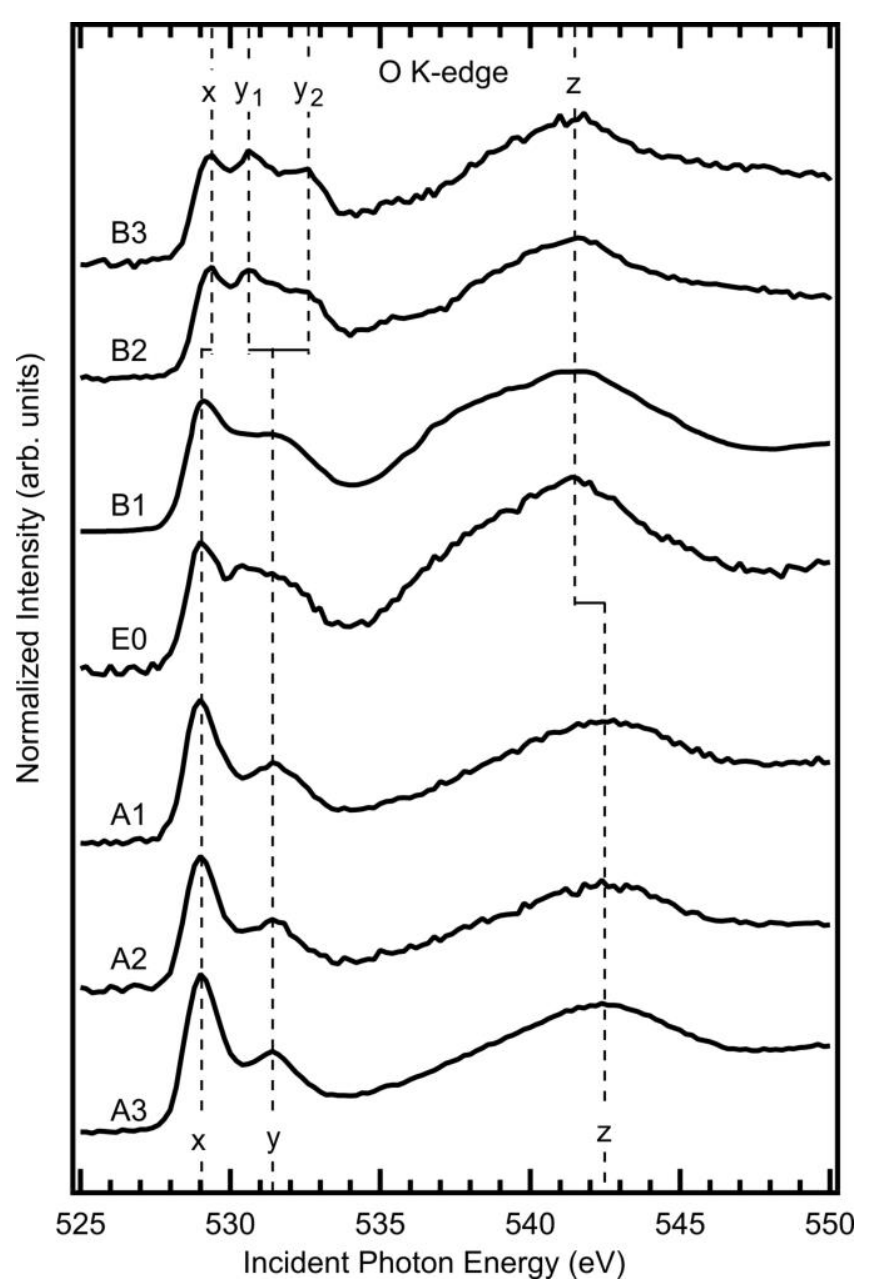

Figure 2. Oxygen K-edge absorption spectra measured in total electron yield mode for all samples deposited at different $\mathrm{pH}$, under basic ('B', top three spectra), neutral ('E0', middle spectrum), and acidic ('A', bottom three spectra) conditions. The pre-edge energy region $(528-534 \mathrm{eV})$ originates from a transition of an $\mathrm{O} 1 s$ electron to hybridized $\mathrm{O} 2 p \mathrm{Mn} 3 d$ states and is sensitive to the $\mathrm{MnO}_{x}$ phase. (cf. Fig. S3)

The spectrum for sample B1 exhibits a lower absorption at this energy than the spectra for sample B2 and B3. For sample A1, the absorption in this energy region is higher when compared to the other two samples of the same group. The $L_{2}$ edge shows indication of similar changes. These subtle, but continuous spectral changes indicate a continuous change in the composition of formed $\mathrm{MnO}_{x}$ phases. In addition to the spectral change at $641.6 \mathrm{eV}$, the spectrum of sample B1 shows an intensity change in the high energy shoulder at approximately $643.0 \mathrm{eV}$ that doesn't occur in the spectra of group ' $A$ ', indicating that the samples of group ' $\mathrm{B}$ ' contain a different set of $\mathrm{MnO}_{\mathrm{x}}$ phases than the samples of group ' $A$ ' (vide infra).

To obtain a more comprehensive picture of the changes in the $\mathrm{MnO}_{\mathrm{x}}$ electronic structure, additional XAS spectra at the oxygen
K-edge were taken in the energy range from 525 to $550 \mathrm{eV}$ (Fig. 2). When interpreting the spectra regarding individual electronic contributions, two regions can be separated: The first is the pre-edge region from approximately 528 to $534 \mathrm{eV}$, exhibiting well-defined peaks originating from a hybridization of O $2 p$ and $\mathrm{Mn} 3 d$ states. This region provides complementary information about the Mn oxidation state, ligand field, and bonding. The second is the energy region above approximately $535 \mathrm{eV}$ containing broad and less defined structures, which relate to a hybridization of $\mathrm{Mn} 4 s$ and $4 p$ states with the $\mathrm{O} 2 p$ conduction bands. ${ }^{[33-35]}$

A shift of the pre-edge features to lower energies indicates an increase of the Mn oxidation state, ligand field, and bonding. Another indicator for the $\mathrm{MnO}_{\mathrm{x}}$ phase is the ratio of the first two features (' $x$ ' and ' $y$ ' in Fig. 2). The $\mathrm{O}$ K-edge spectra of $\mathrm{MnO}_{2}$ and birnessite that both contain $\mathrm{Mn}^{4+}$ show a clear dominance of feature ' $x$ ' compared to feature ' $y$ ' (Fig. S3), as in the literature. ${ }^{[31]}$ For the samples examined herein, the highest ratio of these peaks is found for the samples of group ' $A$ ', indicating a significant proportion of $\mathrm{Mn}^{4+}$ is present in these samples. Samples B2 and B3 on the other hand, exhibit a one to one ratio and a splitting of feature ' $y$ ' into two separate peaks (' $y_{1}$ ' and ' $y_{2}$ ' in Fig. 2). Similar shape of the ' $\mathrm{y}$ ' feature is observed in $\mathrm{O} K$ edge spectra of $\mathrm{Mn}_{2} \mathrm{O}_{3}$ and $\mathrm{Mn}_{3} \mathrm{O}_{4}$, comprising $\mathrm{Mn}^{3+}$ (Fig. S3). The samples $\mathrm{B} 1$ and $\mathrm{E} 0$ show an intermediate ratio of the features ' $x$ ' and ' $y$ ' and a broadening of feature ' $y$ ', indicating an intermediate oxidation state between the acidic or more basic samples. These findings agree well with the conclusions deduced from the spectra at the $M n \mathrm{~L}_{2,3}$-edges (vide supra), indicating that a high proton activity (low $\mathrm{pH}$ value) during preparation favors the formation of $\mathrm{MnO}_{x}$ in a higher oxidation state. The second region in the $\mathrm{O} K$-edge spectra also exhibits a clear change between the two groups. The energetic position of peak ' $z$ ' for the samples of group ' $B$ ' is shifted about $1 \mathrm{eV}$ to lower energy compared to the samples of group ' $A$ ', indicating a higher localization of the underlying electronic transitions to the hybridized $\mathrm{O} 2 p-\mathrm{Mn} 4 s, 4 p$ states. Interestingly, this shift is observed for sample E0 that - together with sample B1 - more closely resembles the spectra of group ' $A$ ' in the pre-edge region. In addition, peak ' $z$ ' appears broader for these two samples compared to the other samples. This feature is sensitive to changes in the electronic structure caused by the Mn-O bond length, ${ }^{[31]}$ suggesting a higher variety of bond lengths in the sample, which could be caused by a stronger mixing of different $\mathrm{MnO}_{x}$ phases or decreased long-range order in samples $\mathrm{B} 1$ and $\mathrm{E} 0$. 


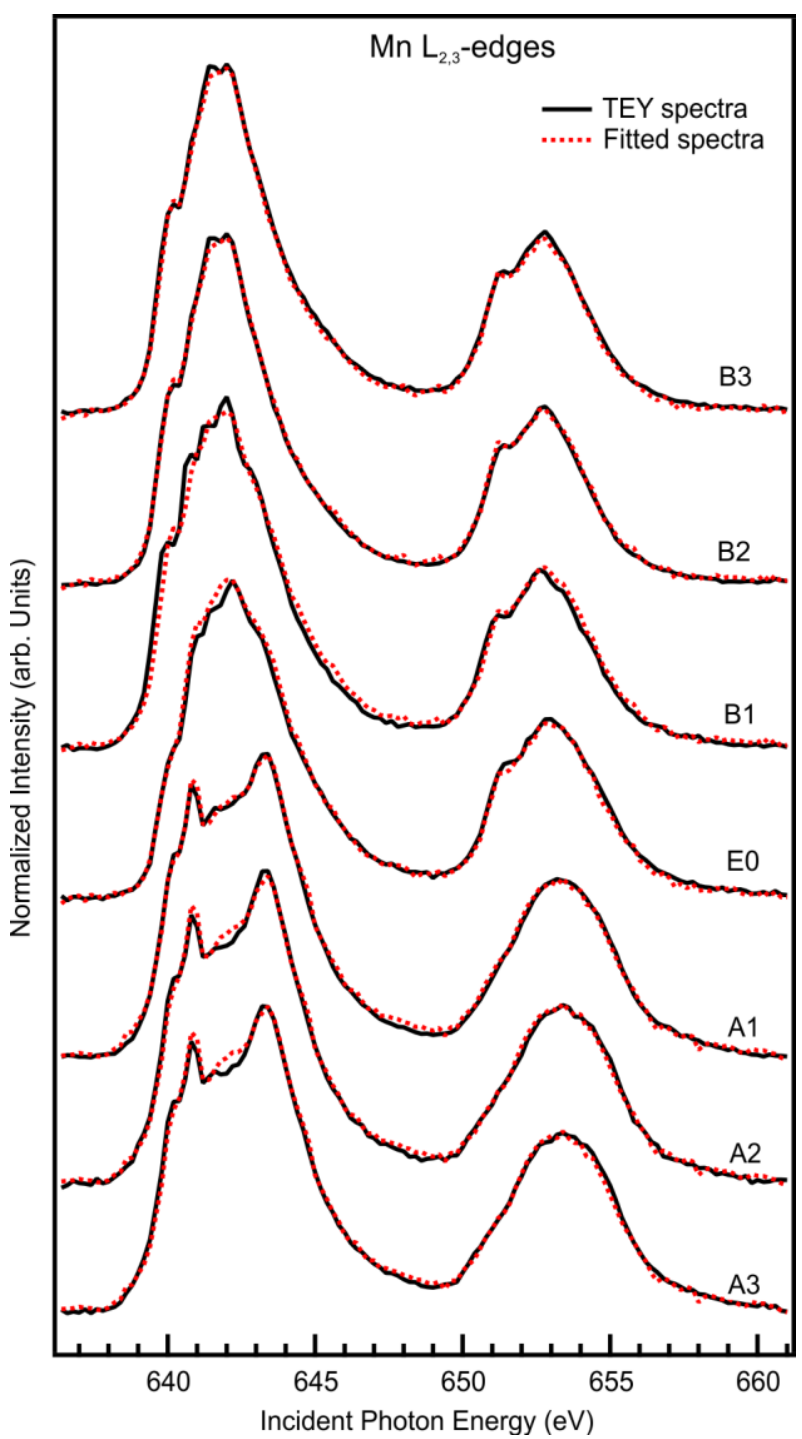

Figure 3. $\mathrm{Mn}_{2,3}$-edges absorption spectra of the investigated samples (solid lines) and the corresponding linear combination fittings as a superposition of the reference spectra (dotted lines).

In conclusion of this part, the analysis of both, the $\mathrm{Mn} \mathrm{L}_{2,3}$-edges and the $\mathrm{O}$ K-edge absorption spectra show that the sample deposited close to neutral $\mathrm{pH}$ exhibits clear characteristics of both $\mathrm{Mn}^{3+}$ and $\mathrm{Mn}^{4+}$ along with a low content of $\mathrm{Mn}^{2+}$. In a next step, the amount of contributing phases is estimated in a more quantitative fashion. For this, the spectra were evaluated by applying a linear combination fitting method utilizing well-defined reference spectra.

The spectral features at the $M n L_{2,3}$-edges are unique for each $\mathrm{MnO}_{x}$ phase, therefore, the fitting procedure can be used to provide insight into the proportion of $\mathrm{Mn}$ existing in different phases within one sample. ${ }^{[36]}$ The linear combination fitting method was found to be an applicable method in the case of mixed oxidation states and multiple phases. ${ }^{[37]}$ This allows tracking of the composition of $\mathrm{Mn}$ phases within the samples, which can be correlated to the variation of the $\mathrm{pH}$ during electrodeposition. The fitting procedure utilized previously

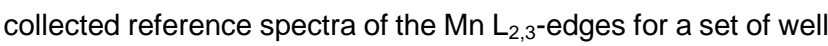
characterized $\mathrm{MnO}_{\mathrm{x}}$ samples, ${ }^{[38]}$ viz. $\mathrm{Mn}^{2+}$ resembling the spectra of $\mathrm{MnO}, \mathrm{Mn}_{3} \mathrm{O}_{4}, \mathrm{Mn}_{2} \mathrm{O}_{3}, \mathrm{MnO}_{2}$ and birnessite (Fig. 1 bottom \& Fig. S2). Prior to the fitting, all spectra were normalized to the off-resonance background and a linear background subtraction was applied (for details see SI). The spectra of the investigated samples (Fig. 1 top panel), were fitted by linear combinations of the $\mathrm{MnO}_{\mathrm{x}}$ reference spectra (Fig. 1 bottom panel) at the $\mathrm{Mn}_{2,3}$-edges to quantify the contributions of $\mathrm{MnO}_{x}$ species in each sample. The aforementioned linear combination fitting procedure allowed a superposition of the reference spectra that strongly resemble the sample spectra in all cases (Fig. 3). The fitting indicates sample compositions of primarily three $\mathrm{MnO}_{\mathrm{x}}$ phases, viz. $\mathrm{Mn}_{2} \mathrm{O}_{3}, \mathrm{Mn}_{3} \mathrm{O}_{4}$, and birnessite, while the contribution of $\mathrm{Mn}^{2+}(\mathrm{MnO})$ and $\mathrm{MnO}_{2}$ was found to be below $10 \%$ (Fig. 4 \& Table S1). Furthermore, a complementary fitting procedure based on the $\mathrm{O} \mathrm{K}$-edge spectra gave comparable results for the sample compositions (vide infra, Fig. S4, S5 \& Table S2).

The fitting approach herein reveals that the samples of group ' $A$ ' consist predominately of a birnessite-like phase with $\mathrm{Mn}_{3} \mathrm{O}_{4}$ (58$62 \%$ and $31-33 \%$ respectively, Fig. 4 \& Table S1) while the samples of group 'B' consist of a mixture of $\mathrm{Mn}_{2} \mathrm{O}_{3}$ and, to a lesser extent, $\mathrm{Mn}_{3} \mathrm{O}_{4}$ (57-79\% and 21-29\% respectively; Fig. 4 \& Table S1). For the samples deposited closest to neutral conditions, viz. A1, E0, and B1, the sample composition is highly $\mathrm{pH}$ dependent: The amount of birnessite gradually decreases with increasing $\mathrm{pH}$ while the amount of $\mathrm{Mn}_{2} \mathrm{O}_{3}$ shows an abrupt rise when increasing the $\mathrm{pH}$ towards near neutral deposition

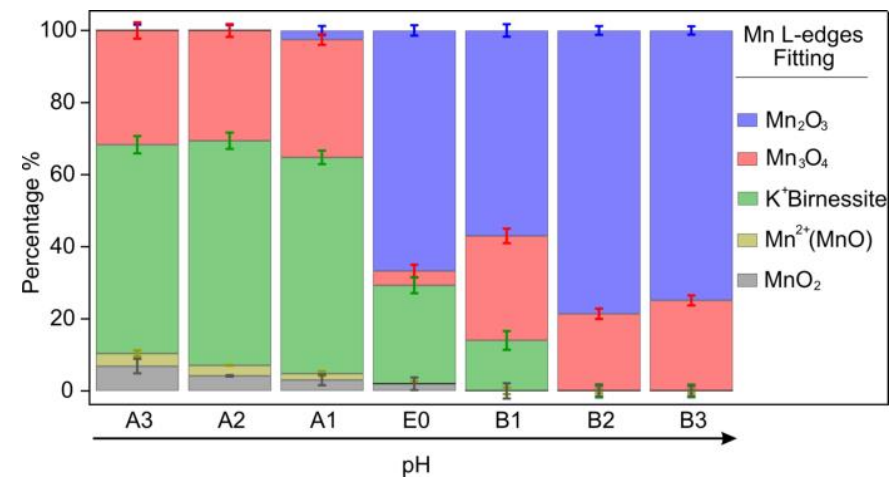

Figure 4. Percentages of $\mathrm{MnO}_{x}$ phases contained in the samples deposited at different $\mathrm{pH}$ identified by the linear combination fitting procedure (experimental and simulated curves are shown in Fig 3). The contributions of $\mathrm{K}+$ Birnessite, $\mathrm{Mn}_{2} \mathrm{O}_{3}, \mathrm{Mn}_{3} \mathrm{O}_{4}, \mathrm{Mn}^{2+}$ resembling $\mathrm{MnO}$ and $\mathrm{MnO}_{2}$ are shown for each sample and plotted with error bars of \pm 1 standard deviation. However, the total accuracy is estimated to be approximately $\pm 5 \%$. Tabulated values for the contributions are provided in Table S1. 
conditions. In addition, the sample deposited at near neutral conditions, viz. E0, shows a notably reduced amount of $\mathrm{Mn}_{3} \mathrm{O}_{4}$ and is composed almost entirely of $\mathrm{Mn}_{2} \mathrm{O}_{3}$ and birnessite. To cross-check the fitting parameters obtained for the $\mathrm{Mn}$ $\mathrm{L}_{2,3}$-edges spectra, these parameters were used to create a linear superposition of O K-edge reference spectra. Hereby, the O K-edge spectra of the samples could be accurately reproduced (Fig S4). A further optimization using the same algorithm as for the $\mathrm{Mn}$ spectra did not led to a major improvement (Fig S4), suggesting that the parameters are coherent for the $\mathrm{Mn}_{2,3}$-edges and $\mathrm{O} K$-edge spectra. Thus, the phase contributions found for the $\mathrm{O}$ K-edge fitting are comparable (Table S2 \& Fig S5).

Interestingly, these findings imply that it is not an increase in abundance of one specific "catalytic active $\mathrm{MnO}_{x}$ phase" that can be related to the enhanced catalytic activity for samples $A 1$, $\mathrm{E} 0$, and B1. Otherwise, a continuous increase/decrease of the catalytic activity - with either group 'A' group 'B' being more active - would be expected rather than a maximum activity for the sample (E0). While the amount of $\mathrm{Mn}_{3} \mathrm{O}_{4}$ is nearly constant for the samples of group ' $A$ ' and ' $B$ ', sample $E 0$ shows nearly no contribution of this phase. Since $\mathrm{Mn}_{3} \mathrm{O}_{4}$ possesses a low OER catalytic activity, ${ }^{[30,39]}$ the absence of this phase may contribute to the high catalytic activity of sample E0. This, however, cannot explain the higher catalytic activity of the samples A1 and B1 compared to the other two samples of their respective groups, all containing a comparable amount of $\mathrm{Mn}_{3} \mathrm{O}_{4}$. A different composition of $A 1$ and $B 1$ compared to the other two samples of group 'A' and 'B' respectively, was previously suggested. ${ }^{[30]}$ The fitting approach herein reveals that both samples $A 1$ and $\mathrm{B} 1$, have contributions of birnessite and $\mathrm{Mn}_{2} \mathrm{O}_{3}$, although in different ratios (30:1 and $1: 4$, respectively; Table S1). Meanwhile, sample E0 displays the highest catalytic activity and contains birnessite $\left(\mathrm{Mn}^{3+} / \mathrm{Mn}^{4+}\right)$ and $\mathrm{Mn}_{2} \mathrm{O}_{3}\left(\mathrm{Mn}^{3+}\right)$ phases in a ca. 1:2.5 ratio.

When interpreting these results it is important to consider that this study is restricted to an ex situ analysis of the samples, i.e. without applied potential, and further phase transformation is likely to occur when applying a potential. The most thermodynamically stable phase under operational conditions is likely to be that indicated by the Pourbaix diagram. However, this does not formally consider kinetic barriers nor the potential importance of disorder. As such, it is possible that different phases in the initial material affect the structural phase formed in situ / operando. Of course, other sample properties that are not accessible with the technique used herein can also influence the catalytic activity. XAS can provide valuable information about the total contribution of $\mathrm{MnO}_{x}$ phases present in the sample, but their spatial distribution, adjacent phases, and grain size are not accessible. Such properties may influence the extent of structural disorder, which is often also important for catalysis. Thus, despite determining the ratios of $\mathrm{MnO}_{\mathrm{x}}$ phases in the sample series, it is not possible to make a clear correlation towards catalytic activity. The findings may still be tentatively connected to $\mathrm{MnO}_{x}$ properties that have been proposed as being important for OER catalysis.

One of these properties is a variety of $\mathrm{Mn}-\mathrm{O}$ bond lengths, which are suggested to be important to high catalytic activity of $\mathrm{MnO}_{x}$ towards the OER. ${ }^{[40]}$ This is supported by the observation of broad features in the region denoted ' $z$ ' in the O K-edge spectra herein (Figure 2), which are sensitive to electronic structure changes correlated to the $\mathrm{Mn}-\mathrm{O}$ bond lengths. This broadening is most pronounced for the samples $E 0$ and $B 1$, while the composition of the most catalytically active samples (A1, E0, and $\mathrm{B} 1$ ), appeared to be very sensitive to the $\mathrm{pH}$ as they were deposited closest to neutral conditions. As such, it may be speculated that local fluctuations in the $\mathrm{pH}$ during deposition could lead to a greater number of structural distortions.

Recent studies showed that disturbance of a birnessite structure by doping it with other $3 d$ transition metals can enhance the catalytic activity of the material. ${ }^{[41-43]}$ Such a structural disturbance might also be reached by a judicious choice of the parameters in the electrodeposition process. However, examination of the spatial phase distribution and/or structural distortions is beyond the capabilities of the specific experimental technique used herein - consequently suggesting a promising area for future study.

\section{Conclusion}

$\mathrm{MnO}_{x}$ films were electrodeposited from $\mathrm{Mn}$ (II) acetate in ethylamonium nitrate at $120{ }^{\circ} \mathrm{C}$ with different $\mathrm{pH}$. Samples prepared under these conditions were previously shown to have differing electrocatalytic activity towards water oxidation. Herein, soft X-ray absorption spectroscopy has been performed at the $\mathrm{Mn}_{2,3}$-edges and the $\mathrm{O} \mathrm{K}$-edge aiming to identify the sample compositions and relate those to the previously observed changes in the catalytic activity. The analysis of the absorption spectra revealed an increase of the mean $\mathrm{Mn}$ oxidation state correlated with electrodeposition at lower $\mathrm{pH}$. The samples are comprised of three groups, those deposited under acidic, near neutral and basic conditions, with each group showing a distinctive spectral fingerprint. However, the samples with the 
highest catalytic activity from the acidic and the basic group, viz. $A 1$ and B1, exhibited slight differences in spectral shape compared to the other two samples of their respective groups. Linear combination fitting of reference spectra reveals samples from both groups contain significant amounts of $\mathrm{Mn}_{3} \mathrm{O}_{4}$, but the samples from acidic deposition are predominately birnessite, while the samples from basic deposition are largely $\mathrm{Mn}_{2} \mathrm{O}_{3}$. The sample previously described as the most catalytically active (E0), was largely comprised of $\mathrm{Mn}_{2} \mathrm{O}_{3}$ and birnessite with minimal $\mathrm{Mn}_{3} \mathrm{O}_{4}$. No direct correlation of a specific phase with high catalytic activity is possible. While those results revealed no specific $\mathrm{MnO}_{x}$ phase dominating the catalytically more active samples, the phase composition of the three most active samples appeared to be most sensitive to a $\mathrm{pH}$ variation.

These findings indicate that the presence of a single active phase does not cause the enhanced catalytic activity, but that other effects might play an important role, such as: structural disorder and distortions, the interplay of different phases, or the lack of phases inhibiting the catalytic reaction.

Moreover, herein it is demonstrated that the ratio of the contributing phases can be tuned by a careful choice of preparation conditions. For future catalyst (electro)synthesis these findings can be utilised to prepare structural phases in desired ratios to enhance and study the activity of $\mathrm{MnO}_{x}$ water oxidation catalysts.

Keywords: Manganese Oxides; X-ray Absorption Spectroscopy; Water Oxidation Catalysis; Electrodeposition; Mixed Oxidation States

\section{Acknowledgements}

M.N.S. thanks the Deutscher Akademischer Austausch Dienst (DAAD) for the award of a doctoral scholarship (Funding no. 91527148) and the Physics Department, Faculty of Science, Alexandria University, Egypt; and S.A.B. acknowledges funding from the Deutsche Forschungsgemeinschaft through SPP 1601. The authors are grateful to Dr. R. Golnak (HelmholtzZentrum Berlin für Materialien und Energie $\mathrm{GmbH}$, Berlin, Germany) for assistance during the synchrotron beamtime.

\section{References}

[1] N. S. Lewis, D. G. Nocera, PNAS 2006, 103, 15729 15735.

[2] N. S. Lewis, Science 2016, 351, aad1920.

[3] T. Faunce, S. Styring, M. R. Wasielewski, G. W. Brudvig, A. W. Rutherford, J. Messinger, A. F. Lee, C. L. Hill, H. deGroot, M. Fontecave, et al., Energy \& Environmental Science 2013, 6, 1074.
[4] A. J. Bard, M. A. Fox, Accounts of Chemical Research 1995, 28, 141-145.

[5] H. Dau, C. Limberg, T. Reier, M. Risch, S. Roggan, P. Strasser, ChemCatChem 2010, 2, 724-761.

[6] M. Wiechen, M. M. Najafpour, S. I. Allakhverdiev, L. Spiccia, Energy Environ. Sci. 2014, 7, 2203-2212.

[7] K. N. Ferreira, T. M. Iverson, K. Maghlaoui, J. Barber, S. Iwata, Science 2004, 303, 1831-1838.

[8] J. Barber, Chem. Soc. Rev. 2008, 38, 185-196.

[9] W. Rüttinger, G. C. Dismukes, Chem. Rev. 1997, 97, 124.

[10] Y. Umena, K. Kawakami, J.-R. Shen, N. Kamiya, Nature 2011, 473, 55-60.

[11] J. Yano, J. Kern, K. Sauer, M. J. Latimer, Y. Pushkar, J. Biesiadka, B. Loll, W. Saenger, J. Messinger, A. Zouni, et al., Science 2006, 314, 821-825.

[12] R. K. Hocking, R. Brimblecombe, L.-Y. Chang, A. Singh, M. H. Cheah, C. Glover, W. H. Casey, L. Spiccia, Nat Chem 2011, 3, 461-466.

[13] Y. Gorlin, B. Lassalle-Kaiser, J. D. Benck, S. Gul, S. M. Webb, V. K. Yachandra, J. Yano, T. F. Jaramillo, J. Am. Chem. Soc. 2013, 135, 8525-8534.

[14] A. Indra, P. W. Menezes, I. Zaharieva, E. Baktash, J. Pfrommer, M. Schwarze, H. Dau, M. Driess, Angewandte Chemie International Edition 2013, 52, 13206-13210.

[15] J. Park, H. Kim, K. Jin, B. J. Lee, Y.-S. Park, H. Kim, I. Park, K. D. Yang, H.-Y. Jeong, J. Kim, et al., J. Am. Chem. Soc. 2014, 136, 4201-4211.

[16] I. Zaharieva, P. Chernev, M. Risch, K. Klingan, M. Kohlhoff, A. Fischer, H. Dau, Energy Environ. Sci. 2012, 5, 7081-7089.

[17] T. Takashima, K. Hashimoto, R. Nakamura, J. Am. Chem. Soc. 2012, 134, 1519-1527.

[18] A. Singh, R. K. Hocking, S. L.-Y. Chang, B. M. George, M. Fehr, K. Lips, A. Schnegg, L. Spiccia, Chem. Mater. 2013, 25, 1098-1108.

[19] M. Huynh, C. Shi, S. J. L. Billinge, D. G. Nocera, Journal of the American Chemical Society 2015, 137, 14887-14904.

[20] A. Indra, P. W. Menezes, M. Driess, ChemSusChem 2015 8, 776-785.

[21] I. Zaharieva, D. González-Flores, B. Asfari, C. Pasquini, M. R. Mohammadi, K. Klingan, I. Zizak, S. Loos, P. Chernev, H. Dau, Energy Environ. Sci. 2016, 9, 2433-2443.

[22] R. Pokhrel, M. K. Goetz, S. E. Shaner, X. Wu, S. S. Stahl, Journal of the American Chemical Society 2015, 137, 8384-8387.

[23] M. Fekete, R. K. Hocking, S. L. Y. Chang, C. Italiano, A. F. Patti, F. Arena, L. Spiccia, Energy \& Environmental Science 2013, 6, 2222.

[24] R. K. Hocking, R. Malaeb, W. P. Gates, A. F. Patti, S. L. Y. Chang, G. Devlin, D. R. MacFarlane, L. Spiccia, ChemCatChem 2014, 6, 2028-2038.

[25] R. K. Hocking, H. J. King, A. Hesson, S. A. Bonke, B. Johannessen, M. Fekete, L. Spiccia, S. L. Y. Chang, Australian Journal of Chemistry 2015, 68, 1715.

[26] I. Zaharieva, M. M. Najafpour, M. Wiechen, M. Haumann, P. Kurz, H. Dau, Energy \& Environmental Science 2011, 4 $2400-$

[27] M. Wiechen, I. Zaharieva, H. Dau, P. Kurz, Chem. Sci. 2012, 3, 2330-2339.

[28] M. Huynh, D. K. Bediako, D. G. Nocera, Journal of the American Chemical Society 2014, 136, 6002-6010.

[29] D. González-Flores, I. Zaharieva, J. Heidkamp, P. Chernev, E. Martínez-Moreno, C. Pasquini, M. R. Mohammadi, K. Klingan, U. Gernet, A. Fischer, et al., ChemSusChem 2016, 9, 379-387.

[30] F. Zhou, A. Izgorodin, R. K. Hocking, L. Spiccia, D. R. MacFarlane, Adv. Energy Mater. 2012, 2, 1013-1021.

[31] B. Gilbert, B. H. Frazer, A. Belz, P. G. Conrad, K. H. Nealson, D. Haskel, J. C. Lang, G. Srajer, G. De Stasio, J. Phys. Chem. A 2003, 107, 2839-2847.

[32] S. P. Cramer, F. M. F. DeGroot, Y. Ma, C. T. Chen, F. Sette, C. A. Kipke, D. M. Eichhorn, M. K. Chan, W. H. Armstrong, Journal of the American Chemical Society 1991, 113, 7937-7940. 
[33] F. M. F. de Groot, M. Grioni, J. C. Fuggle, J. Ghijsen, G. A. Sawatzky, H. Petersen, Phys. Rev. B 1989, 40, 57155723.

[34] R. Qiao, T. Chin, S. J. Harris, S. Yan, W. Yang, Current Applied Physics 2013, 13, 544-548.

[35] P. Rez, Xudong Weng, Hong Ma, Microscopy Microanalysis Microstructures 1991, 2, 143-151.

[36] M. Khan, E. Suljoti, A. Singh, S. A. Bonke, T. Brandenburg, K. Atak, R. Golnak, L. Spiccia, E. F. Aziz, J. Mater. Chem. A 2014, 2, 18199-18203.

[37] A. Manceau, M. A. Marcus, S. Grangeon, American Mineralogist 2012, 97, 816-827.

[38] M. Khan, J. Xiao, F. Zhou, M. Yablonskikh, D. R. MacFarlane, L. Spiccia, E. F. Aziz, ChemSusChem 2015, 8, 1980-1985.
[39] K. Maeda, K. Domen, The Journal of Physical Chemistry Letters 2010, 1, 2655-2661.

[40] A. Ramírez, P. Hillebrand, D. Stellmach, M. M. May, P. Bogdanoff, S. Fiechter, The Journal of Physical Chemistry C 2014, 118, 14073-14081.

[41] A. C. Thenuwara, S. L. Shumlas, N. H. Attanayake, E. B. Cerkez, I. G. McKendry, L. Frazer, E. Borguet, Q. Kang, M. J. Zdilla, J. Sun, et al., Langmuir 2015, 31, 12807-12813.

[42] A. C. Thenuwara, E. B. Cerkez, S. L. Shumlas, N. H. Attanayake, I. G. McKendry, L. Frazer, E. Borguet, Q. Kang, R. C. Remsing, M. L. Klein, et al., Angewandte Chemie International Edition 2016, 55, 10381-10385.

[43] G. Elmaci, C. E. Frey, P. Kurz, B. Zümreoğlu-Karan, Inorg. Chem. 2015, 54, 2734-2741. 